\title{
Figure and tables
}

\section{FIGURE}

2.1 Example of institutional levels relevant for analysis of public procurement of innovation

\section{TABLES}

2.1 The Hommen matrix extended 27

2.2 Institutional dimensions affecting innovative public procurement 45

3.1 Key events in the public procurement of an innovative maritime radio system

4.1 Institutional barriers to adoption identified and corresponding coordination activities

5.1 Organizations involved and their main types of rationalities 104

5.2 Collaborators and their specific efforts indicating their specific rationalities

6.1 Milestones and events leading to the establishment of the biogas and upgrading plant

6.2 Summary of identified target groups and purpose of interaction in the biofuel case

6.3 Rationalities to include in interaction for the public procurement of innovation

7.1 Cases of public procurement of innovation $\quad 145$

7.2 Important dates in the procurement project 153

7.3 Key events of the passive houses case 156 